\title{
ATOR-DRAMATURGO: ESTUDOS CORPOGRÁFICOS EXPANDIDOS
}

\author{
Juliano Ricci Jacopini \\ Doutorando em Artes da Cena (UNICAMP) \\ Mestre em Educação - Conhecimento, Linguagem e Arte(UNICAMP) \\ Pedagogo (USP) \\ Colaborador Artístico da Casa PIPA (Plataforma Internacional de Produção Artística) www.casapipa.art.br \\ Ator/ Pesquisador (Cia. Labirinto de Teatro) www.cialabirinto.com.br \\ E-mail: jjacopini@yahoo.com.br
}

Este preâmbulo traz reflexões acerca de um estudo sobre corpografia, onde o ator, em processo criativo, tece uma dramaturgia cênica e uma cena dramatúrgica, por intermédio e acionamento de suas memórias pessoais, que servem de rico material para a possibilidade nascente do ator-dramaturgo nos estudos das artes da cena.

Ator-dramaturgo. Corpografia. Memória.
This preamble brings reflections on a study of corpography, where the actor in the creative process builds a scenic dramaturgy and dramaturgical scene through his personal memories, which act as a rich material for the growing possibility of the actor-playwright studies in the arts scene.
Keywords

Actor-playwright. Corpography. Memory. 
De início vi algo como minha mãe me buscando como se eu houvesse sumido. Após, quando parei em um lugar, senti eu mesma em uma busca por mim.

Mabê Henrique - Diário de bordo do dia 05 de Maio de 2015.

Os caminhos, ao se pensar arte, em seu amplo acontecimento, tornam-se cada vez mais plurais, e ainda, plurais de si mesmos. Quais os desejos (sendo este desejo pensado na perspectiva deleuziana, como intensidade, não sendo relativo à falta) que nos levam a ter um encontro com a arte de forma que ela nos revele algo sobre nós mesmos (tanto ator/ bailarino/ performer e público)?

Caminho para possível reflexão se faz pelo olhar - da/na cena - significado sobre o campo expandido, onde criação e ação cênica se constroem na busca pela intensificação da relação entre arte e vida, onde o artista passeia por ' $n$ ' linguagens para dar forma a suas inquietações e inquietações do público que se torna atuante da cena.

Ao seguir nessa premissa em pensar a arte no campo expandido, será trazido o lugar de artista da cena para dialogar com a ideia de campo expandido junto à pesquisa que vem sendo desenvolvida sobre a corpografia - movimento em que o corpo, em estado de criação se inscreve no tempo que escreve uma dramaturgia, uma busca construída por intermédio da memória feita das corporeidades em ação - junto à Cia. Labirinto de Teatro ${ }^{1}$, da cidade de Matão/SP.

Imbricar a corpografia ao campo expandido suscita gestos de pensamento em um dos pilares de discussão de ambos conceitos: o trabalho do artista sobre si, sendo este si, trabalhado sob viés de pesquisa prática-criativa da possibilidade nascente do ator-dramaturgo que cria a cena dramática e dramatúrgica, simultaneamente.

Não há nestes escritos a intenção de encontrar um preenchimento total com sentido. José Gil (2002) alude à ideia de preenchimento total que só é válido enquanto poroso, pois o sentido se dá na percepção do encontro. Ainda, se construirmos uma relação sobre o sentido de gesto, não se busca a finalidade, mas sua transição, pois é a chegada e saída dele que comunica de alguma forma. E é está uma pesquisa em transição, buscando formas de se comunicar.

Partindo da possibilidade da pesquisa corpográfica relacionada ao campo expandido, de primazia, é possível pensar algo a partir da ideia de 'desmontagem' da ação cênica (vendo ação cênica como todo acontecimento de uma criação, desde o processo até sua execução final 'espetacular'). Desnudar o processo criativo poderia dar margem à expansão para que o público tivesse acesso à intimidade do nascedouro das ideias, que, tomado na perspectiva do trabalho do artista sobre si, revela o artista em sua singularidade, e, que enfoca essa singularidade como o cerne de criação de sua obra, fugindo do esperado, criando e sendo criado em outro (não) lugar, produzindo uma presença cênica de autoria plena, com a possibilidade de ressignificada diante do seu vivido.

Outra conexão se faz plausível no âmbito da teatralidade do teatro. Sendo o artista do campo expandido performer do espaço teatral, onde a cena e sua plasticidade se edificam desvinculados dos padrões, possível criar

\footnotetext{
${ }^{1}$ Disponível em: <www.cialabirinto.com.br>
} 
novos espaços que dão vazão ao campo criativo em uma modificação do sujeito - artista e público - empregando ao teatro algo maior que o teatro, o que Grotowski nomeou de 'arte como veículo', pois o campo expandido é uma relação experiencial com a arte.

Por esta ótica, a corpografia apresenta relação ao campo expandido, como dito anteriormente, no que diz respeito ao trabalho do artista sobre si, e será tratada, neste breve preâmbulo, com porosidade de pensamento, onde a escrita de uma dramaturgia nasce de um corpo dramático e dramatúrgico e, para isso, toma a memória pessoal como fundamental para a composição criacional, revelando o artista para o público e para si mesmo, com o convite de se revisitar no hoje, com abertura para recontar sua história, na possibilidade de ficcionalizar as experiências pessoais que tecem uma ação cênica.

Segundo Bergson (2006), a memória nasce em uma linha sucessiva de fatos que se atualizam em evolução. Movimentar a memória, que sumariamente seria lembrar algo (ir ao passado) se dá na premissa de buscar caminhos de vir a ser (pela subjetivação) de memórias que poderão ter sido vividas, ou não, mas atravessadas e acessadas em infinitos pontos que atualizam a memória no presente, compondo molduras que são forças que determinam, no caso, o fluxo criativo dos atores/ pesquisadores sobre a corpografia, em processo da tessitura do drama. Assim, a tessitura do drama se dá pelo presente, já que é o presente que determina a memória. As composições dos atores constroem uma dramaturgia cênica (partituras corporais costuradas da nascente de ações físicas) e uma cena dramatúrgica (texto dramatúrgico advindo da memória e dialogado no processo criativo) por seus corpos em trabalho.

Expandir o campo de pesquisa criativa para si mesmo e em si mesmo, revela um trabalho fundamentado sobre a própria vida que, de alguma forma, serve de aparato para reconstruir significações. Mario Biagini (2013) trata que:

\begin{abstract}
Qualquer práxis humana pode ser o fundamento de um trabalho sobre a vida. Não falo metaforicamente, quero dizer trabalho sobre vida no sentido literal: a própria vida, um material como a madeira para o carpinteiro ou as sementes e as plantas para o jardineiro. Mas, em nome de quê há que se trabalhar sobre a própria vida? (Biagini, 2013, p. 178).
\end{abstract}

Talvez, para que se chegue a conhecer a si mesmo e assim, conhecer o outro, ou reconhecer-se no outro "[...] é como se a própria vida estivesse implorando para ser vivida em uma outra intensidade." (Biagini, 2013, p. 178).

$\mathrm{O}$ ator, como carpinteiro, e seu corpo, como a madeira. Quem esculpe seu corpo é o tempo - sua memória - que, quando incluído como matéria do trabalho é imensurável e perecível. É no corpo que vive a memória (o material mais autoral de cada sujeito) e, na pesquisa corpográfica, é o corpo acionado a visitar o vivido, tirando o artista do "platô dos hábitos", onde não apenas experimenta, mas ganha experiência.

Portanto, na corpografia, é o corpo-memória do ator que expande o campo de seu trabalho criacional. É no ator que está a vida criativa: em sua vida estão acontecimentos para a criação, guardados em memórias pessoais, revisitadas e reterritorializadas constantemente. Deleuze e Guattari (2012), em seus escritos sobre o pensamento e a produção, ilustram a ideia de "pensamento rizomático", que, se transferirmos para a prática de trabalho de 
ator, corresponderia à raiz central, e as criações dos atores, às ramificações desta raiz. De qualquer lugar pode nascer algo.

Criação e imaginação são tomados corpo graficamente do ponto de vista da teoria da pulsão de ficção, elaborada por Suzi Sperber (2009). Para a pesquisadora, a capacidade de criar é inata e presente em todo ser humano, e se transborda de capacidade para fazer criações, levada por tomadas de emoções do profundo ser e de fatos vividos, portanto, que fazem parte da memória. Ao criar, joga-se com o imaginário, com o simbólico e com a efabulação, o que reveste a criação de uma autoria plena do ser humano.

Abrir o pensamento sobre a corpografia, correlacionando-a ao estudo do campo expandido, revela-se em pensar arte em um horizonte maior, onde não se busca uma técnica para criar, mas sim, o desenvolvimento da própria técnica amparada por técnicas de interesse que mapeiam a tentativa de, pela prática, desenvolver a própria linguagem.

Como exemplo: na pesquisa sobre a corpografia que vem sendo desenvolvida faz-se uso dos caminhos da técnica de mímesis corpórea $^{2}$ desenvolvidas pelo Grupo Lume Teatro ${ }^{3}$. Porém, a técnica se reveste pelos interesses próprios dos estudos corpográficos com a memória em um desdobramento do trabalho do ator pela mímesis de si (conceito que vem sendo desenvolvido nesta pesquisa). Cabe ressaltar que não há intenção alguma em tomar o conceito de mímesis, qual quer que o seja, ultrapassado, mas sim, de enxergá-lo alargado, afinal, não há como pensar arte sem repre- sentação. Os meios são os mesmos, porém, os lugares que se chega transitam por outros vieses de interesse, onde, ao se distanciar do objeto observado para representá-lo, o ator se aproxima de um latência em si mesmo - presente, vivida e atualizada em um si, num eterno devir-outro.

Cassiano Quilici (2014), apoiado na reflexão de Joseph Beuys (2011) de que "[...] cada homem, um artista" trata sobre "[...] resgatar o sentido artístico que nossas atividades podem adquirir, contrapondo-o às formas de trabalho alienado e à racionalização instrumental da produção" (Quilici, 2014, p. 13). Portanto, no reconhecimento de que todo sujeito é autor de sua arte, e assim, tem seus meios para criar, tornando sua criação de caráter legítimo e significativo, o que se estende para o público, evidencia que o mesmo pode vir a se reconhecer na obra artística também pelos seus interesses, pelos atravessamentos que a obra os/nos toca. Criar, então, é um caminho singular de cada sujeito, sendo ele ator, atuador ou espectador da ação cênica, "[...] diz respeito à capacidade do homem ser centro irradiador de um mundo a partir do reconhecimento das energias latentes nas matérias e do uso dos recursos culturais." (Quilici, 2014, p. 13)

O campo expandido torna a percepção uma ação e não uma mera recepção passiva. Empregá-lo nos estudos corpográficos pode ser pensado no trabalho do artista sobre si como um encontro com um estranho que é familiar, via conceito bergsoniano de atualização da memória formativa e/ou inventiva no presente do ator-dramaturgo que cria a dramaturgia,

\footnotetext{
${ }^{2}$ A mímesis corpórea não é a imitação estereotipada de um corpo que se observa, mas o desenvolvimento e expansão do olhar para que seja possível absorver diferenças que compõem a corporeidade de um indivíduo a ser estudado, um olhar que detecta informações que podem até mesmo estar revestidas pelo cotidiano de um corpo, e que imprimem no ator uma memória para seu corpo. (Ferracini, 2006).

${ }^{3}$ Disponível em: <www.lumeteatro.com.br>.
} 
porém, sob uma nova ótica de composição. 0 corpo em cena, por si, sem a palavra, já está carregado de leituras possíveis para os espectadores, porém, a ideia corpográfica é, através da dramaturgia do corpo, criar um corpo dramatúrgico.

O teatro tal como concebemos no ocidente está ligado ao texto e por ele limitado. Para nós, no teatro a Palavra é tudo e fora dela não há saída; o teatro é um ramo da literatura, uma espécie de variedade sonora da linguagem, e se admitimos uma diferença entre o texto falado em cena e o texto lido pelos olhos, se encerramos o teatro nos limites daquilo que aparece entre as réplicas, não conseguimos separar o teatro da idéia do texto realizado. (Artaud, 1984, p. 90).

Portanto, também, ao pensar na possibilidade do ator-dramaturgo, temos a nascente dramatúrgica no corpo que compõe uma escrita-em-movimento ou uma escrita-em-ação. Na tentativa por uma composição cênica onde a dramaturgia nasça junto aos corpos em criação, busca-se expressar a linguagem por aquilo que ela costumeiramente não expressa, buscando sua nascente através de algo novo, a fim de dividi-la no espaço, considerando-a sob uma forma de encantamento (Artaud, 1984).

Assim, existe um saber artesanal que vai sendo construído no trabalho do ator sobre si, que serve de base para interlocução com o público em um exercício de construção de caráter e de se exercer no mundo numa perene construção de si, em modos de ser e existir que vão modificando sentidos da identidade e atravessando os sujeitos envolvidos com um ação cênica de forma que todos se vejam e dialoguem com a obra, em âmbitos sensíveis, perceptíveis, signícos.
Trabalhar à luz do campo expandido coloca a verdade em evidência como demonstração/ desvelamento para modificar a si mesmo para ter acesso à experiência do verdadeiro que modifica o modo de existência (Foucalt, 1985), identificando nossos atos com nossos pensamentos e não extraindo pensamentos de nossos atos, em uma estética de recepção tanto para o artista quando para o público: ambos são premidos a abandonar o hábito. É preciso que cada um se perceba no espaço para que se possa perceber no mundo, assim, cria-se o objeto, cria-se um mundo possível, afinal, o que se procura enquanto movimento - enquanto ação cênica - é um movimentar a vida. Ao expandir o olhar, seja na pesquisa corpográfica ou outras diversas pesquisas do campo das artes da cena, o artista, artesão de si, passa a se olhar e se (re)conhecer em sua arte, que o possibilita um acesso à sua vida para chegar à vida do outro, não para tocá-la, mas para que o outro se sinta à vontade e convidado para tocar a si mesmo, para perceber em si uma potência de vida que é privilégio seu, próprio, de total e inacabável fonte de (re) criação, escrevendo sua história em si mesmo, ou ainda, reconhecendo em si grande e plena capacidade dramatúrgica de se inventar sempre.

Nas investigações processuais, o objetivo é refletir sobre as possibilidades da construção de um corpo dramático e dramatúrgico, que escreve, no ato da criação, uma dramaturgia da cena e uma cena dramatúrgica, usando, para isto, referenciais externos e pessoais, como a memória com suas variações (que incluem a imaginação), como elemento que potencializa os processos criativos.

Especificamente, tratando de 'Ame!' (um dos processos de estudos corpográfico da Cia. 
Labirinto de Teatro), o trabalho se engendra pelas memórias pessoais da intérprete Mabê Henrique, que são entrelaçadas a obras plásticas selecionadas do artista Amedeo Modigliani, em um trabalho fundamentado na pesquisa de mímesis corpórea, que, para a construção dramatúrgica vem se desdobrando na possibilidade de conceituar a mímesis da memória e a mímesis de si: referenciais importantes de pesquisa para tessitura dramática e dramatúrgica.

Quando minha mãe recebeu a notícia de que havia uma (ou duas) crianças para a adoção, ela rezou. Rezou muito perguntando a Deus se aquela criança poderia ser um de seus filhos, se ela poderia ser capaz de dar o mesmo amor em mesma dose, nem menos por não ser de sangue e nem mais por piedade.

"Sim!" foi a resposta divina (e minha, pois juro que apanhei como minha irmã e fui mimada como meu irmão). [...] Por isso creio na construção do amor. Minha mãe acreditou nele desde o momento que Deus lhe disse "sim" e ainda acredita, por isso existe e se reinventa. Sou grata! Me tornei uma "bonequinha de luxo" e infelizmente são poucas as que tiveram e tem tanta sorte.

(Mabê Henrique - extraído do Diário de Bordo de 29 de Abril de 2015)

Este fragmento traz uma memória da atriz sobre uma história que sua mãe adotiva lhe contou sobre a decisão ao adotá-la: as inseguranças, a busca em Deus e a percepção própria da atriz sobre "sorte". Faz parte de um depoimento narrado e escrito de uma memória pessoal que foi utilizado para o processo criativo junto às matrizes corporais do quadro "Retrato de Lunia Czechovska" (1919), de Amedeo Modigliani e fotografias da mãe adotiva da atriz.

Trabalhando com este material, em pro- cesso criativo, a atriz passa a deixar que seu corpo traga memórias involuntárias que são despertadas por estes referencias externos (memórias escritas, fotos, pinturas, etc), dialogadas entre si e que, no caso, possibilitaram a extensão dramatúrgica do corpo para o fragmento a seguir:

Lunia - (colocando o véu sobre a cabeça) Eu só espero que ela não desgoste de mim!

(Dirigindo-se para trás de uma das cadeiras, entrando assim, em um confessionário. Ajoelha-se no confessionário) Estou muito feliz pela notícia que recebi! Não minto que esperava por isso há tempos, mas algo me aflige (vira a cabeça para a cadeira).O senhor acha que sou capaz de criar essa menina? Digo, de dar o amor que ela merece, nem menos por não ter vindo de mim e nem mais por piedade? Será que Deus quer o mesmo que eu? Sem dúvida ele não a colocaria em meu caminho se não fosse sua vontade, mas não há como não ficar agoniada com o acontecimento.

(Levanta do confessionário e eleva os olhos para o céu)

Deus, me dê forças, e, caso seja esse o meu caminho, que eu seja capaz de segui-lo.

(Respira longo e aliviada e, encaminha-se para a cadeira da Cigana) [...] (Extraído do texto "Ame!" em processo contínuo de construção pela escrita corpográfica)

Quando o corpo passa a estar pronto para a busca, e, em estado de busca, reage à relação com outro corpo, com o que o cerca, com o que the é representado instaura-se um trabalho dialógico, ora com outro corpo, ora com obras plásticas, ora com memórias, ora com símbolos. Ocasiona-se um movimento de viver o corpo d'outro por essa memória (re)criativa que se encontra com o passado e o atualiza, ou, (re)encontra-se com o presente de outra forma e o simboliza, ou ainda (re)direciona o futuro e o poetiza. 
[...] a recriação é reencontro com o passado, mas de um passado incompleto na memória datada, que pode, portanto, ser recriado em novos voos através de imagens, que completam as lacunas da memória. (Hirson, 2011, p.

29).

Assim se tece uma dança das memórias em um território energético com alusões e referências vividas, buscando como e o que o corpo exprimirá neste vivido do agora, que nasce com/ pela potência de expressão. Corpografar pode ser pensado como uma reterritorialização do/no território: eu me aproprio de algo que existe e ressignifico frente meus gestos de experimentação, pela re-interpretação e pelo interesse. Busca-se, assim, uma reorganização disso mesmo. Em uma máxima deleuziana de que "a única coisa que se repete na vida é a diferença". O corpo se revisita e cria uma ficção de si mesmo, dramática e dramatúrgica.

Encontrar-se em si mesmo, eis um ponto primordial do trabalho do ator. É no ator que está a vida criativa: em sua vida estão acontecimentos para a criação, guardados em memórias pessoais, revisitadas e reterritorializadas constantemente.

Qualquer tipo de busca de organicidade e vida requer experimentar relações e a única forma é experimentar com uma técnica qualquer, pois experimentar é dar tempo à própria experiência. $O$ intuito de querer foge da relação de receber e receber é uma abertura para si mesmo que se revela por verdades presentes no profundo íntimo de cada ser, portanto, legítimas e de autoria plena. Esta autoria criativa se estende na corpografia, e então, o ator-dramaturgo joga com suas memórias e compõe uma dramaturgia vinda e alimentada por referenciais pessoais, atualizados e ressignificados no encontro, no entre.

\section{Referências}

ARTAUD, A. O teatro e seu duplo. São Paulo: Max Limonad, 1984.

BERGSON, H. Matéria e Memória. São Paulo: Martins Fontes, 2006.

Memória e Vida. São Paulo: Martins Fonte, 2006.

BEUYS, J. Cada Homem um Artista. Porto: 7 de Nós Editora, 2011.

BIAGINI, M. Desejo sem Objeto. In: Revista Brasileira Estudos da Presença. Porto Alegre, v. 3, n. 1, p. 176-197, jan./abr. 2013.

DELEUZE, G; GUATARRI, F. Mil Platôs: capitalismo e esquizofenia. 2. ed. São Paulo: Editora 34, 2012. v. 5.

FERRACINI, R. Corpos em Arte, Corpos em fuga. In: FERRACINI, R. (Org.). São Paulo: Aderaldo e Rothschild: Fapesp, 2006.

GIL, J. Movimento Total. São Paulo: Iluminuras, 2002.

HIRSON, R. Alphonsus de Guimaraens: Reconstruções da Memória e Recriações no Corpo. Tese (Doutorado em Artes da Cena) - Instituto de Artes, Universidade Estadual de Campinas, Campinas: 2011.

QUILICI, C. O campo expandido: arte como ato filosófico. Sala Preta, Brasil, v. 14, n. 2, p. 12-21, dez. 2014.

SPERBER, S. Ficção e razão: uma retomada 
das formas simples. São Paulo, SP: Aderaldo \&Rothschild, 2009.

Recebido em 08/12/2015

Aprovado em 25/05/2016 